\title{
IgG4-related disease with tracheobronchial miliary nodules and asthma: a case report and review of the literature
}

\author{
Xiuling Wang ${ }^{1,2}$, Jun Wan ${ }^{1 *}$, Ling Zhao ${ }^{3}$, Jiping $\mathrm{Da}^{3}$, Bin $\mathrm{Cao}^{1}$ and Zhenguo Zhai ${ }^{1}$
}

\begin{abstract}
Background: IgG4-related disease (IgG4-RD) is a systemic autoimmune disease that can affect multiple organs of the body. Pulmonary manifestations of IgG4-RD include pulmonary solid nodules, thickening of bronchovascular bundles, interstitial involvement, and ground glass opacities. Here we present a rare case of IgG4-RD with tracheobronchial nodules and review the relevant literature.

Case presentation: A 52-year-old man was admitted to our hospital with a history of intermittent cough for 27 months and recurrent wheezing for 17 months. He had been diagnosed with asthma prior to admission and was responsive to oral prednisone (30 mg/day, with gradual tapering). Bronchoscopy performed 2 years prior to admission showed tracheal and bronchial mucosal hyperemia, edema, and miliary nodules. Pathological tests showed chronic inflammation with focal lymphocytic infiltration in the bronchial mucosa. The patient had recurrent cough and wheezing after prednisone was stopped or the dose reduced. At the time of admission to our hospital, his serum immunoglobulin G4 (lgG4) level had increased to $7.35 \mathrm{~g} / \mathrm{L}$. Following bronchoscopy, the lgG4 expression in the bronchial mucosa was compared with that observed during the last two bronchoscopies. Bronchoscopy performed 7 months prior to admission revealed lgG4+ plasma cell infiltration in the bronchial tissue, with > 10 IgG4+ plasma cells per high power field and an lgG4+/lgG+ cell ratio of $>40 \%$. The current bronchoscopy revealed a decrease in IgG4 expression in the bronchial tissue, probably because of the intermittent prednisone treatment. The case fulfilled the comprehensive clinical diagnostic criteria for IgG4-RD. He received prednisone and azathioprine, and he has never developed recurrence.

Conclusions: Our case exhibited three important clinical indication: First, tracheobronchial miliary nodules could be the presentation of IgG4-related disease. Second, IgG4-related disease with pulmonary involvement has close connection with asthma. Last, lgG4-related disease can be very sensitive to prednisone, the infiltration of lgG4 positive plasma cells decreased after prednisone treatment and symptoms significantly improved in our case. In conclusion, we reported the first case of IgG4-RD presenting with miliary nodules on the tracheal and bronchial tube walls combined with asthma. The findings will further our understanding of the characteristics of IgG4-RD.
\end{abstract}

Keywords: IgG4-related disease, Pulmonary involvement, Tracheobronchial nodules

\footnotetext{
* Correspondence: blueswan2013@yahoo.com

${ }^{1}$ Center for Respiratory Diseases, China-Japan Friendship Hospital:

Department of Pulmonary and Critical Care Medicine, China-Japan Friendship

Hospital; National Clinical Research Center for Respiratory Diseases, Peking

University Health Science Center, No 2, East Yinghua Road, Chaoyang District,

Beijing 100029, People's Republic of China

Full list of author information is available at the end of the article
}

(c) The Author(s). 2019 Open Access This article is distributed under the terms of the Creative Commons Attribution 4.0 International License (http://creativecommons.org/licenses/by/4.0/), which permits unrestricted use, distribution, and reproduction in any medium, provided you give appropriate credit to the original author(s) and the source, provide a link to the Creative Commons license, and indicate if changes were made. The Creative Commons Public Domain Dedication waiver (http://creativecommons.org/publicdomain/zero/1.0/) applies to the data made available in this article, unless otherwise stated. 


\section{Background}

IgG4-related disease (IgG4-RD) is a systemic autoimmune disease first described by Hamano $\mathrm{H}$ et al. in 2001 [1]. It is characterized by infiltration of immunoglobulin G4 (IgG4)-bearing lymphoplasmacytic cells in the involved organs, which include the pancreas, biliary tree and gallbladder, major salivary glands, ocular region, lung, and kidneys. Pulmonary manifestations include pulmonary solid nodules, thickening of bronchovascular bundles and interlobular septa, interstitial involvement, and roundshaped ground glass opacities (Table 1). Here we report a pathologically confirmed case of IgG4-RD with tracheobronchial nodules.

\section{Case presentation}

A 52-year-old man was admitted to our hospital with a history of intermittent cough for 27 months and repeated wheezing for 17 months. The patient developed cough and cold 27 months back. The cough aggravated at night and was accompanied by snuffling and a sore throat. After treatment with antibiotics, all symptoms but cough improved, and the cough worsened over time. In the last 17 months, the patient also complained of wheezing accompanied by jelly-like sputum, usually after exposure to cold air. He was then admitted to a local hospital. Lung computed tomography (CT) performed at the local hospital showed infiltration in the left lower lung (Fig. 1), indicating left lower lobe pneumonia. A complete blood count yielded the following results: white blood cells, $5.5 \times 109$ / L; neutrophils, 46.7\%, and eosinophils, 5.3\%. Pulmonary function tests showed normal ventilation function. Bronchoscopy revealed tracheal and bronchial mucosal hyperemia and edema and miliary nodules. Histopathology revealed chronic inflammation of the bronchial mucosa with focal lymphocytic infiltration. The patient was treated with antibiotics, expectorants, and bronchodilators; however, his cough symptoms showed no

Table 1 Usual imaging manifestations of pulmonary involvement of IgG4-RD

\begin{tabular}{|c|c|}
\hline Location & Imaging Manifestations \\
\hline \multirow[t]{3}{*}{ Pulmonary parenchyma [22] } & Ground glass opacities \\
\hline & Solid nodules/masses \\
\hline & Interstitial lung disease \\
\hline Airway/Nasculature [23] & Enlargement of bronchovascular bundle \\
\hline \multirow[t]{2}{*}{ Mediastinum } & Enlargement of lymph node [14] \\
\hline & Mediastinal mass [24] \\
\hline \multirow[t]{3}{*}{ Pleural } & Pleural thickening [25] \\
\hline & Pleural mass [25] \\
\hline & Pleural effusion [26] \\
\hline
\end{tabular}

significant improvement. After 1 month, he caught a cold again and developed cough and wheezing. He was then diagnosed with asthma and treated with prednisone $(30 \mathrm{mg} /$ day orally, with gradual tapering) for 1.5 months. His coughing and wheezing symptoms ameliorated, although they recurred when prednisone was stopped. Bronchoscopy performed 7 months prior to admission (Fig. 2) showed multiple white nodular protuberances in the trachea and bronchus, with mucosal hyperemia and edema. Furthermore, mucosal pathology showed chronic inflammation with focal squamous metaplasia. A large number of eosinophils were found in the bronchoalveolar lavage fluid smear. Prednisone $(30 \mathrm{mg} /$ day $)$ was restarted, but his condition relapsed when the dose was tapered to $5 \mathrm{mg} /$ day. The proportion of eosinophils in the peripheral blood increased to 31\% (absolute blood eosinophil count: $3.21 \times 10^{9} / 1$ ), with a serum IgE level of $4220 \mathrm{IU} / \mathrm{ml}$. On admission to our hospital, his routine physical examination findings were unremarkable. His serum IgG4 level had increased to $7.35 \mathrm{~g} / \mathrm{L}$. Lung CT showed no abnormality. The pulmonary function test results were as follows: TLC \%: 99.2\%, RV \%: 96.6\%, RV/TLC: 93\%, FVC\%: 77.8\%, VT\%:154.1\%, FEV1/FVC: $88.71 \%$, FEV1\%: $83.8 \%$, DLCO-SB\%: $67.8 \%$, DLCO/VA:100.3\%, and the bronchial dilation test was positive. His symptoms and pulmonary function test results were consistent with the diagnosis of asthma. However, the inhalation treatment (Symbicort turbuhaler, 160/4.5 micrograms/inhalation, 1 inhalation twice a day) cannot improve his symptoms. We give him a repeated bronchoscopy which suggested scattered alleviated nodules under the tracheobronchial wall without obvious mucosal hyperemia and edema, which improved a lot compared with the bronchoscopy 7 months ago. (Fig. 3). Considering that he is very sensitive to the prednisone, the tissue biopsy obtained at our hospital was stained to identify IgG4 expression and revealed low expression of IgG4 (Fig. 4), with the presence of phlebitis and fibrosis. We detected IgG4 expression in the mucosal tissues from the bronchoscopy performed 7 months earlier. The biopsy showed chronic inflammation with significantly increased plasm cell infiltration and IgG4+ plasma cell infiltration, along with elevated eosinophils. The IgG4+/IgG+ cell ratio was over $40 \%$, and there were more than 10 IgG4+ plasma cells per high power field (HPF) (Fig. 5). The biopsy excluded malignancy and other diseases involving IgG4+ plasma cell infiltration, including sarcoidosis, Wegener's granulomatosis, Churg-Strauss syndrome, and multicentric Castleman's disease. Other laboratory tests of the patient including anti-PR3, anti-MPO ANCA, myositis specific antibody, Anti-nuclear Antibody, ACE, serum G-test, serum GM-test, bacterial and fungal culture of bronchoalveolar lavage fluid (BALF) were 


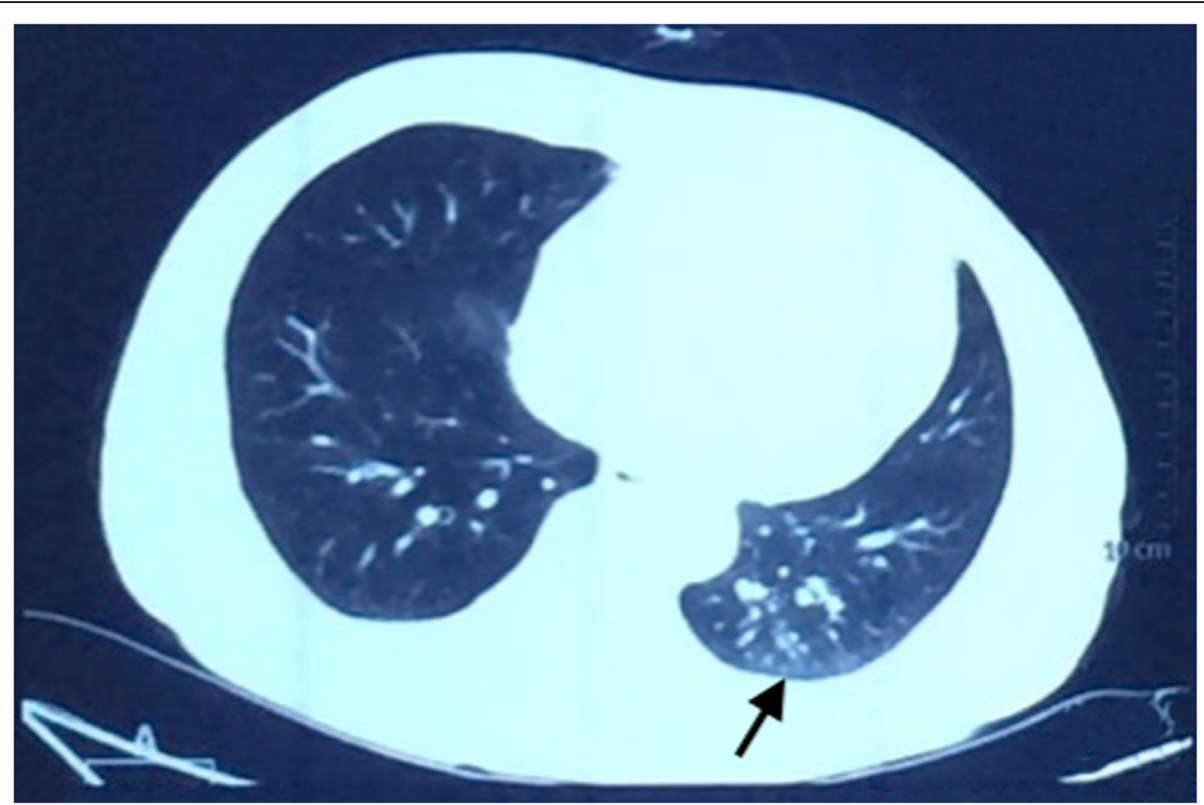

Fig. 1 Lung CT scanning (2014-09-15). Lung CT scanning showed infiltration of left lower lung indicated by an arrow, informing left lower lobe pneumonia

all normal. We excluded other organ involvement, including pancreas dysfunction and retroperitoneal fibrosis. As recommend by the guideline [2], the patient was diagnosed with IgG4-RD and prednisone treatment was continued $(24 \mathrm{mg} /$ day, orally, gradually tapered). He took cyclophosphamide $(100 \mathrm{mg} /$ day $)$ while the prednisone dose was gradually tapered. Currently, he is receiving prednisone $12 \mathrm{mg}$ and azathioprine $100 \mathrm{mg} /$ day with good drug adherence by self-reported, and he has not developed recurrence after hospital discharge. Six months later, his serum IgG4 level and blood eosinophil count decreased to the normal level (serum IgG4: $164 \mathrm{mg} / \mathrm{d}$, blood eosinophil count: $\left.0.12^{*} 10^{\wedge} 9 / 1\right)$. A repeat low dose lung CT scan didn't find new lesions.

\section{Discussion and conclusions}

IgG4-related disease (IgG4-RD) is an emerging immunemediated disease that can affect any body organ. In 1961, Sarles et al. [2] first reported a case of pancreatitis with hypergammaglobulinemia, suggestive of an

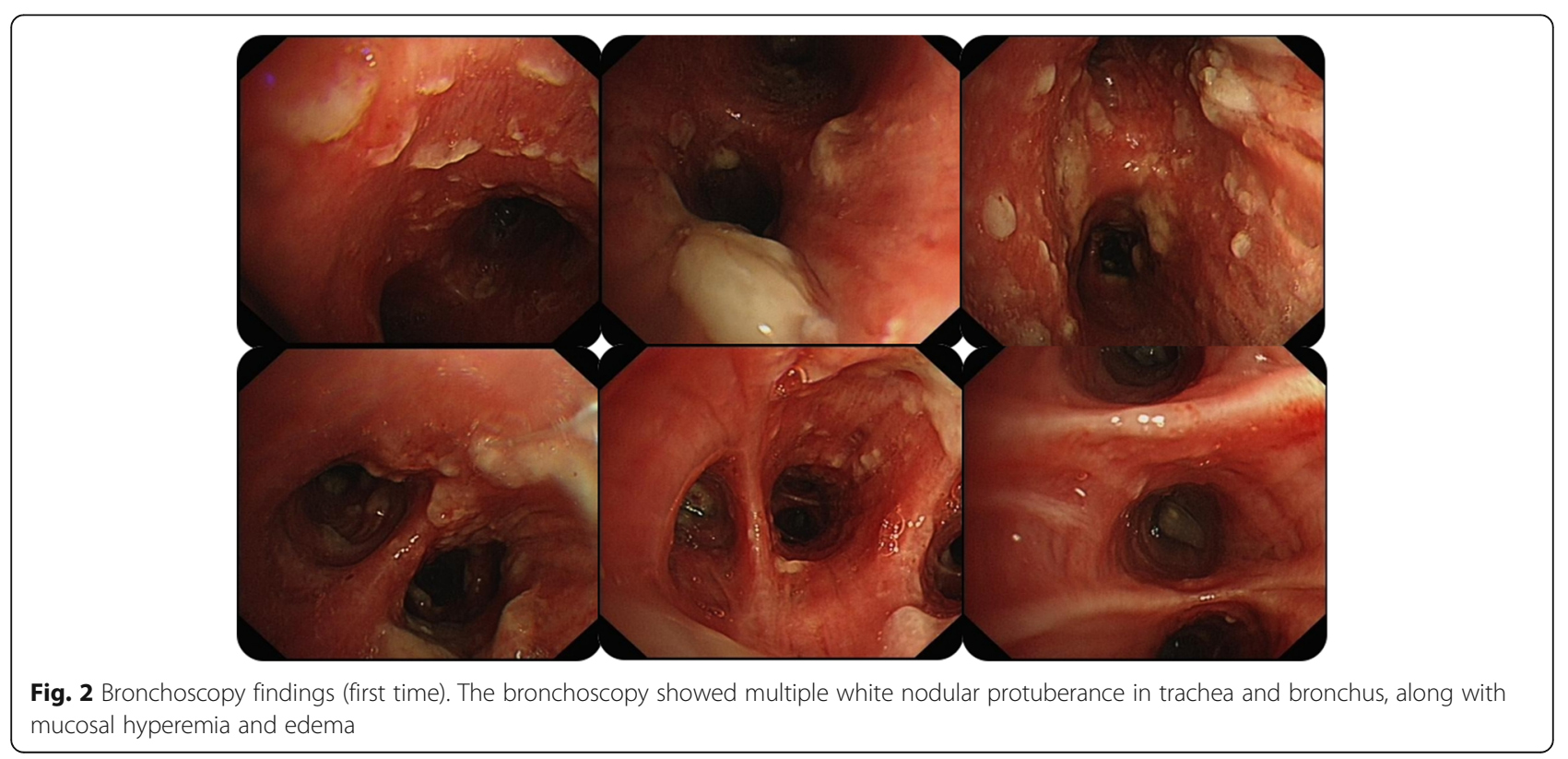




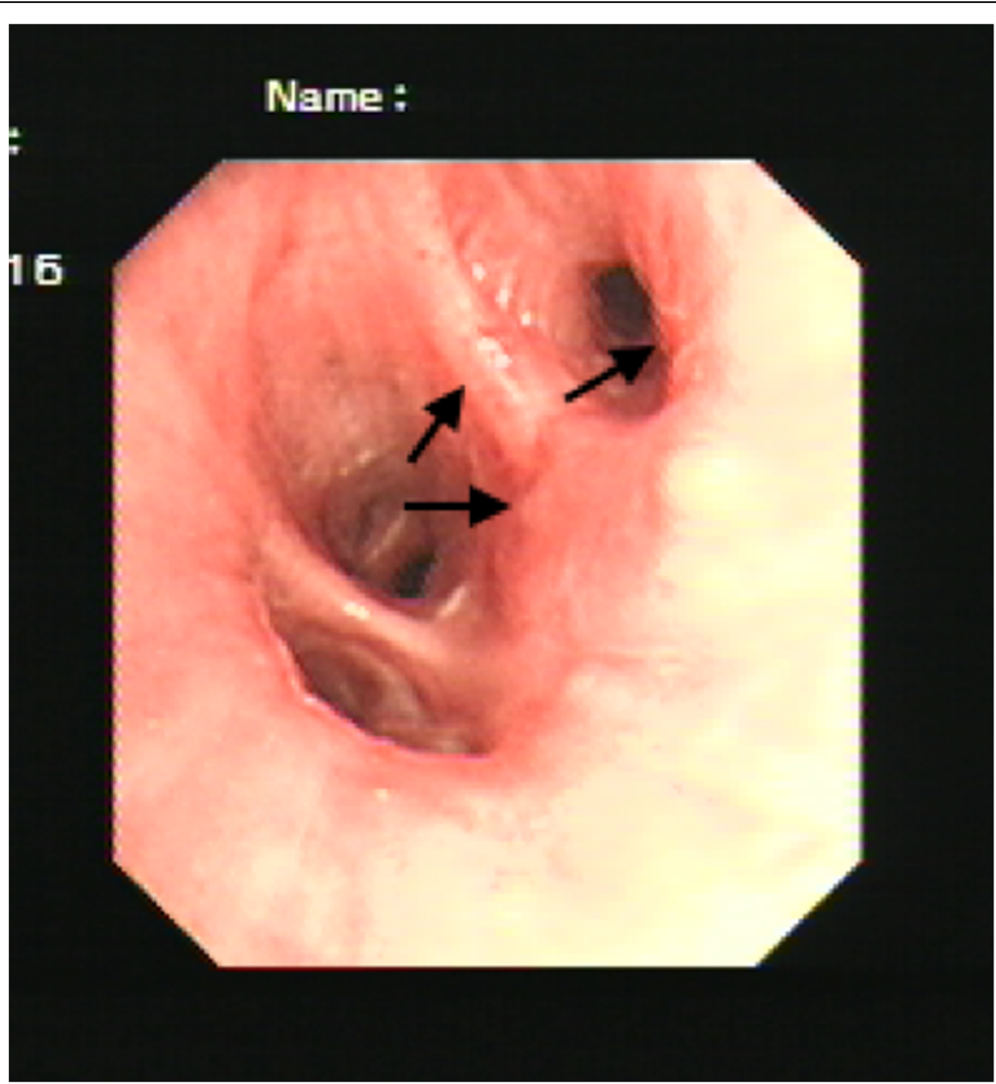

Fig. 3 Bronchoscopy findings (second time). The alleviated miliary nodules on the trachea and bronchus tube wall indicated by arrows

underlying autoimmune process. In 2001, Hamano et al. [1] first established the association between sclerosing pancreatitis and elevated serum concentrations of IgG4. Subsequently, in 2003, Kamisawa et al. [3] found that this autoimmune process is not limited to the pancreas and is actually a systemic disease. The authors introduced the term "IgG4-related autoimmune disease". The term IgG4-RD was finally proposed in 2012 by an international multidisciplinary study group, and a consensus was reached about its pathology [4]. The first management and treatment guidelines for IgG4-RG were published in 2015 [5].
The widespread incomplete understanding of IgG4-RD has led to misdiagnosis of the disease. Because IgG4-RD can be controlled well by glucocorticoids, it is important to study its characteristics for correct diagnosis. In 2012, IgG4-RD study groups in Japan published the first comprehensive clinical diagnostic criteria [6]. The criteria emphasize diffuse/localized swellings or masses in single or multiple organs and elevated serum IgG4 concentrations $(135 \mathrm{mg} / \mathrm{dl})$, with marked lymphocyte and plasmacyte infiltration and fibrosis, infiltration of IgG4+ plasma cells, an IgG4+/IgG+ cell ratio of $>40 \%$, and $>10 \mathrm{IgG} 4+$ plasma cells/HPF in histopathological examination. In

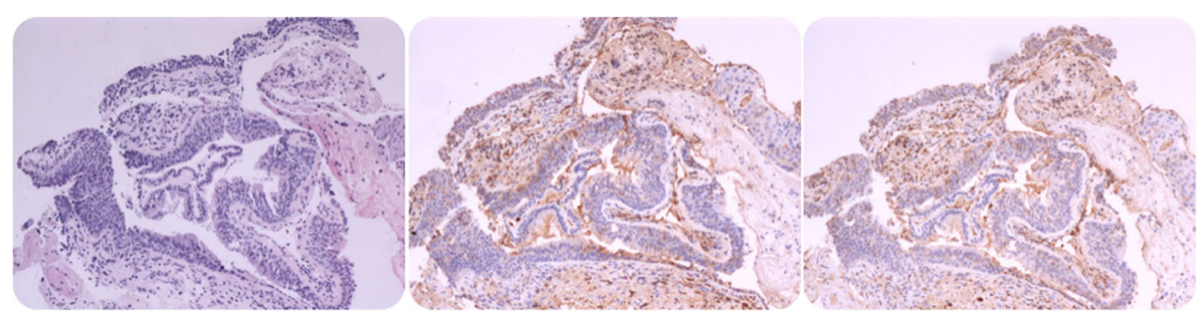

Fig. 4 Tracheal mucosa pathology (first time). Infiltration of lgG4+ plasma cells, the ratio of lgG4+/lgG+ cells $>40 \%$, and lgG4+ plasma cells $>10 / H P F$, figures are as follows separately (from left to right):HE stain magnification 4 times; lgG stain magnification 10 times; lgG4 stain magnification 10 


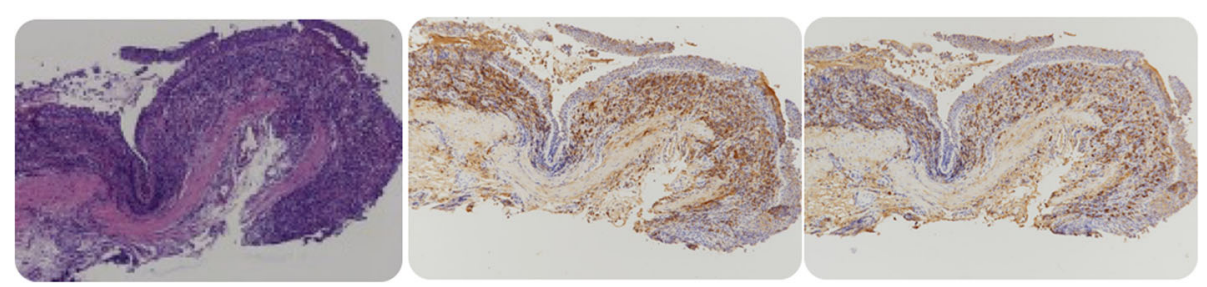

Fig. 5 Tracheal mucosa pathology (second time). The expression of lgG4 decreased in the tissue of 2016. Figures are as follows separately (from left to right):HE stain magnification 10 times; IgG stain magnification 10 times; IgG4 stain magnification 10 times

2015, an international panel of experts [5] further pointed out that the diagnosis of IgG4-RD should be based on comprehensive criteria, including a full clinical history, physical examination, selected laboratory investigations, and appropriate radiological studies. Furthermore, biopsy is strongly recommended for the exclusion of malignancies and other IgG4-RD mimics. In this case report, the serum IgG4 level was substantially increased, and the mucosal biopsy specimen showed infiltration of IgG4+ plasma cells, an IgG4+/IgG+ cell ratio of $>40 \%$, and $>10$ IgG4+ plasma cells/HPF. The patient was responsive to glucocorticoid treatment. Furthermore, his symptoms, physical examination, laboratory tests, and biopsy excluded malignancy and other diseases involving IgG4+ plasma cell infiltration, including sarcoidosis, Wegener's granulomatosis, Churg-Strauss syndrome, and multicentric Castleman's disease. Therefore, the patient's diagnosis of IgG4-RD was confirmed by comprehensive clinical information.

To our knowledge, this is the first reported case of IgG4-RD presenting with miliary nodules on the tracheal and bronchial tube walls, which is a rare type of IgG4-RD. Two other cases of IgG4-RD with isolated tracheobronchial involvement presenting as mass-like lesions have been reported [7, 8], in addition to five cases [9-13] of systemic IgG4-RD with tracheobronchial involvement and tracheobronchial edema or capillary dilatation. We found no difference in pathology between the cases of systemic IgG4-RD and those of isolated tracheobronchial involvement.

Our patient was diagnosed with asthma; he had a positive bronchodilator reversibility test. He suffered from recurrent cough and wheezing that aggravated at night and on exposure to cold air. Furthermore, he had increased eosinophils in the peripheral blood and bronchoalveolar lavage fluid smear. The asthma diagnosis was in line with previous studies reporting patients with a diagnosis of IgG4-RD and asthma $[8,10]$ (Table 2, cases 2 and 6 , respectively). Indeed, several studies and case reports have found connections between IgG4-RD and asthma. A crosssectional study [14] found that 12\% IgG4-RD patients had been diagnosed with asthma. Furthermore,
Flament et al. [15] found that several patients with asthma patients had elevated serum IgG4 concentrations. These patients had significantly high blood eosinophilia, total IgE concentration, and fractional exhaled nitric oxide value.

The increased level of serum IgE in our patient was suggestive of an allergic immunological response in vivo. A previous study found that $44 \%$ patients with autoimmune pancreatitis had allergic diseases [16]. Similarly, other studies found that IgG4-RD and allergic diseases share a common immune characteristic, i.e., the predominance of Th2 cytokines. These can produce the Th2-related cytokine interleukin (IL)10 , which is related to the production of $\operatorname{IgE}$ and IgG4 [17-19]. Jeannin et al. found that Th2-related cytokines could induce the switch from IgE to IgG4 [20]. Other studies proposed that IgG4 can act as a blocking antibody against IgE-mediated allergic responses [21]. However, there is limited evidence to support any relationship between the onset and severity of allergic disease and IgG4-RD. Future studies are required for understanding the pathogenesis of allergic diseases and IgG4-RD and the relationship between them.

IgG4-RD is a newly recognized systemic autoimmune disease. Our case exhibited three important clinical indication: First, tracheobronchial miliary nodules could be the presentation of IgG4-related disease. Second, IgG4related disease with pulmonary involvement has close connection with asthma. Last, IgG4-related disease can be very sensitive to prednisone, the infiltration of IgG4 positive cells decreased after prednisone treatment and symptoms significantly improved in our case. In conclusion, we reported the first case of IgG4-RD presenting with miliary nodules on the tracheal and bronchial tube walls combined with the diagnosis of asthma. The findings from this case may advance our understanding of IgG4-RD and contribute to its diagnosis. Future studies are warranted to aid in early diagnosis and development of suitable therapies. Besides, the relationship between IgG4-related disease and asthma need further exploration. 


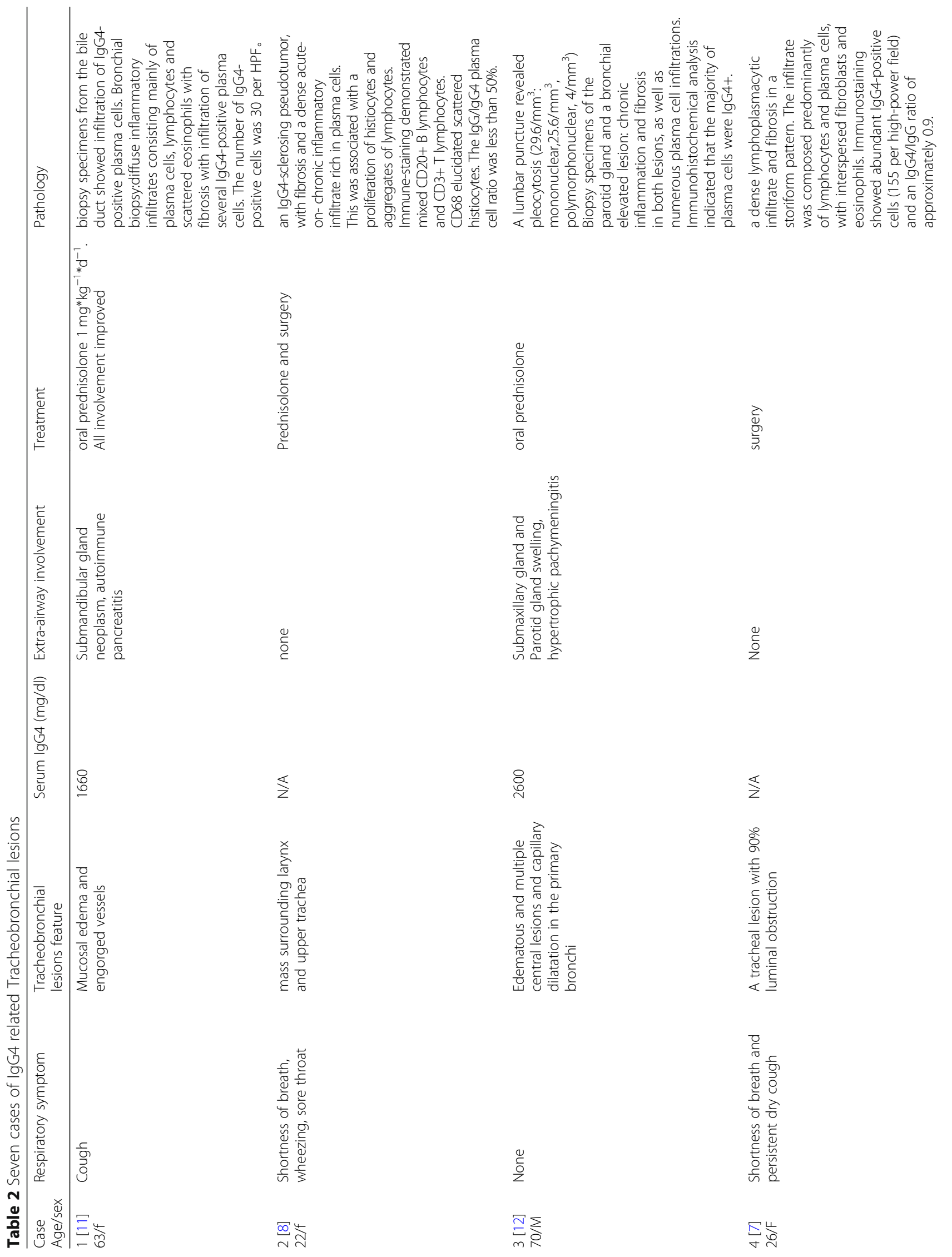




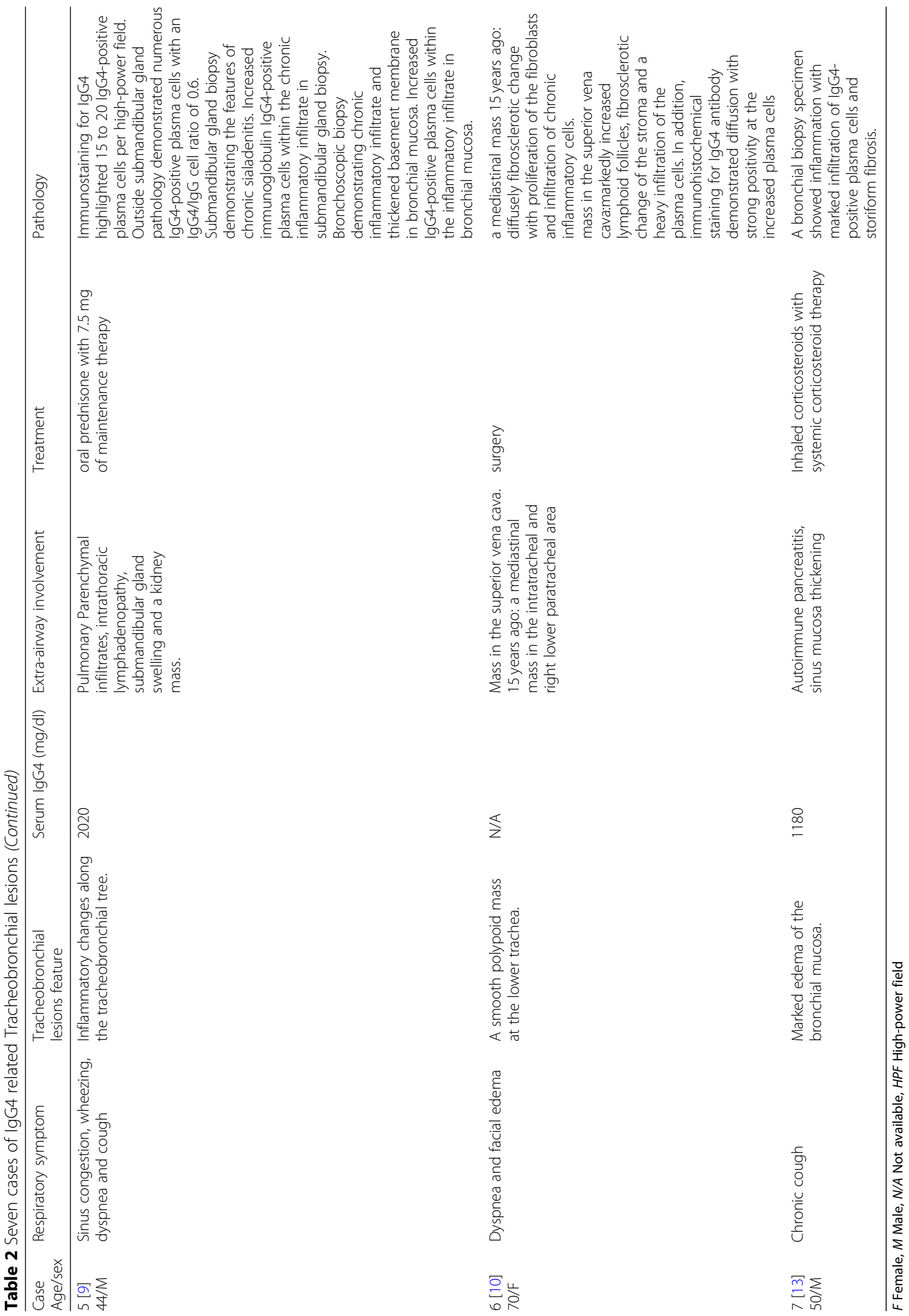




\section{Abbreviations}

CT: Computed tomography; HPF: High power field; IgG4-RD: IgG4-related disease

\section{Acknowledgements}

Not applicable.

\section{Authors' contributions}

JW made substantial contributions to the conception and design, acquisition of data, and analysis and interpretation of data and gave final approval for the version to be published. XW played a major role in the writing of the manuscript. LZ and JD reported the pathological results at our hospital and those obtained 7 months back, assisted in the diagnosis of the patient, and provided advice for documenting the pathological findings in this report. BC and ZZ revised the manuscript critically for important intellectual content. All authors have read and approved the final manuscript, agree to be accountable for all aspects of the work, and will ensure that questions related to the accuracy or integrity of any part of the work are appropriately investigated and resolved.

\section{Funding}

The National Natural Science Fund (81270117). CAMS Innovation Fund for Medical Sciences (CIFMS) (2018-12M-1-003).

This funding body also had no influence on the design of the study and collection, analysis, and interpretation of data and in writing the manuscript.

\section{Availability of data and materials}

The datasets used and/or analyzed during the current study are available from the corresponding author on reasonable request.

\section{Ethics approval and consent to participate}

Our study has received approval from the ethics committee of China-Japan Friendship Hospital.

\section{Consent for publication}

Written informed consent for publication of clinical details and/or clinical images was obtained from the patient. A copy of the consent form is available for review by the Editor of this journal.

\section{Competing interests}

The authors declare that they have no competing interests.

\section{Author details}

'Center for Respiratory Diseases, China-Japan Friendship Hospital; Department of Pulmonary and Critical Care Medicine, China-Japan Friendship Hospital; National Clinical Research Center for Respiratory Diseases, Peking University Health Science Center, No 2, East Yinghua Road, Chaoyang District, Beijing 100029, People's Republic of China. ${ }^{2}$ Fuwai Hospital, National Center for Cardiovascular Diseases, Chinese Academy of Medical Sciences and Peking Union Medical College, No 167, Beilishi Road, Xicheng District, Beijing 100037, People's Republic of China. ${ }^{3}$ Department of Pathology, China-Japan Friendship Hospital, No 2, East Yinghua Road, Chaoyang District, Beijing 100029, People's Republic of China.

Received: 24 May 2018 Accepted: 14 October 2019

Published online: 30 October 2019

\section{References}

1. Hamano H, Kawa S, Horiuchi A, Unno H, Furuya N, Akamatsu T, et al. High serum lgG4 concentrations in patients with sclerosing pancreatitis. N Engl J Med. 2001;344(10):732-8

2. Sarles H, Sarles JC, Muratore R, Guien C. Chronic inflammatory sclerosis of the pancreas-an autonomous pancreatic disease? Am J Dig Dis. 1961;6:688-98.

3. Kamisawa T, Egawa N, Nakajima H. Autoimmune pancreatitis is a systemic autoimmune disease. Am J Gastroenterol. 2003;98(12):2811-2.

4. Deshpande V, Zen Y, Chan JK, Yi EE, Sato Y, Yoshino T, et al. Consensus statement on the pathology of IgG4-related disease. Mod Pathol. 2012;25(9): 1181-92.

5. Khosroshahi A, Wallace ZS, Crowe JL, Akamizu T, Azumi A, Carruthers MN, et al. International Consensus Guidance Statement on the Management and
Treatment of IgG4-Related Disease. Arthritis Rheumatol (Hoboken, NJ). 2015; 67(7):1688-99.

6. Umehara H, Okazaki K, Masaki Y, Kawano M, Yamamoto M, Saeki T, et al. Comprehensive diagnostic criteria for lgG4-related disease (IgG4-RD), 2011. Mod Rheumatol. 2012;22(1):21-30.

7. Kobraei EM, Song TH, Mathisen DJ, Deshpande V, Mark EJ. 2.975. Immunoglobulin g4-related disease presenting as an obstructing tracheal mass: consideration of surgical indications. Ann Thorac Surg. 2013;96(4):e91-3.

8. Virk JS, Stamatoglou C, Kwame I, Salama A, Sandison A, Sandhu G. IgG4sclerosing pseudotumor of the trachea: a case report and review of the literature. Arch Otolaryngol Head Neck Surg. 2012;138(9):864-6.

9. Sekiguchi H, Horie R, Aksamit TR, Yi ES, Ryu JH. 1.01. Immunoglobulin G4related disease mimicking asthma. Can Respir J. 2013;20(2):87-9.

10. Noh D, Park CK, Kwon SY. Immunoglobulin G4-related sclerosing disease invading the trachea and superior vena cava in mediastinum. Eur J Cardiothorac Surg. 2014;45(3):573-5.

11. Ito M, Yasuo M, Yamamoto H, Tsushima K, Tanabe T, Yokoyama T, et al. Central airway stenosis in a patient with autoimmune pancreatitis. Eur Respir J. 2009:33(3):680-3.

12. Yamashita H, Takahashi Y, Ishiura H, Kano T, Kaneko H, Mimori A, et al. Hypertrophic pachymeningitis and tracheobronchial stenosis in lgG4-related disease: case presentation and literature review. Intern Med (Tokyo, Japan). 2012:51(8):935-41.

13. To M, Kono Y, Soeda S, Hara H, Araki K, Kishi H, et al. A case of lgG4-related bronchial disease successfully treated with inhaled corticosteroids. J Allergy Clin Immunol Pract. 2016:4(1):168-70.

14. Zen Y, Nakanuma Y. IgG4-related disease: a cross-sectional study of 114 cases. Am J Surg Pathol. 2010;34(12):1812-9.

15. Flament T, Marchand-Adam S, Gatault P, Dupin C, Diot P, Guilleminault L. What are the characteristics of asthma patients with elevated serum lgG4 levels? Respir Med. 2016;112:39-44.

16. Kamisawa T, Anjiki H, Egawa N, Kubota N. Allergic manifestations in autoimmune pancreatitis. Eur J Gastroenterol Hepatol. 2009;21(10):1136-9.

17. Punnonen J, Aversa G, Cocks BG, McKenzie AN, Menon S, Zurawski G, et al. Interleukin 13 induces interleukin 4-independent lgG4 and lgE synthesis and CD23 expression by human B cells. Proc Natl Acad Sci. 1993;90(8):3730-4.

18. Takeuchi M, Sato Y, Ohno K, Tanaka S, Takata K, Gion Y, et al. T helper 2 and regulatory T-cell cytokine production by mast cells: a key factor in the pathogenesis of lgG4-related disease. Mod Pathol. 2014;27(8):1126-36.

19. Kamisawa T, Takuma K, Egawa N, Tsuruta K, Sasaki T. Autoimmune pancreatitis and lgG4-related sclerosing disease. Nat Rev Gastroenterol Hepatol. 2010;7(7):401-9.

20. Jeannin P, Lecoanet S, Delneste Y, Gauchat JF, Bonnefoy JY. IgE versus IgG4 production can be differentially regulated by IL-10. J immunol (Baltimore, Md : 1950). 1998;160(7):3555-61.

21. Aalberse RC, Stapel SO, Schuurman J, Rispens T. Immunoglobulin G4: an odd antibody. Clin Exp Allergy. 2009;39(4):469-77.

22. Inoue D, Zen Y, Abo H, Gabata T, Demachi H, Kobayashi T, et al. Immunoglobulin G4-related lung disease: CT findings with pathologic correlations. Radiology. 2009;251(1):260-70.

23. Ito S, Ko SB, Morioka M, Imaizumi K, Kondo M, Mizuno N, et al. Three cases of bronchial asthma preceding lgG4-related autoimmune pancreatitis. Allergol Int. 2012;61(1):171-4

24. Inoue M, Nose N, Nishikawa H, Takahashi M, Zen Y, Kawaguchi M. Successfu treatment of sclerosing mediastinitis with a high serum lgG4 level. Gen Thorac Cardiovasc Surg. 2007;55(10):431-3.

25. Choi IH, Jang SH, Lee S, Han J, Kim TS, Chung MP. A case report of IgG4related disease clinically mimicking pleural mesothelioma. Tuberc Respir Dis (Seoul). 2014:76(1):42-5.

26. Ishida A, Furuya N, Nishisaka T, Mineshita M, Miyazawa T. IgG4-related pleural disease presenting as a massive bilateral effusion. J Bronchology Interv Pulmonol. 2014;21(3):237-41.

\section{Publisher's Note}

Springer Nature remains neutral with regard to jurisdictional claims in published maps and institutional affiliations. 